\title{
O espírito de um sobrevivente
}

The survivor's spirit

El espíritu de un sobreviviente

Mônica Mourão Lara Netto ${ }^{1, a}$

monica.mourao@fiocruz.br | https://orcid.org/0000-0002-3976-8901

${ }^{1}$ Fundação Oswaldo Cruz, Instituto de Ciência e Tecnologia em Biomodelos. Rio de Janeiro, RJ, Brasil.

a Especialista em Marketing Empresarial pela Universidade Federal Fluminense.

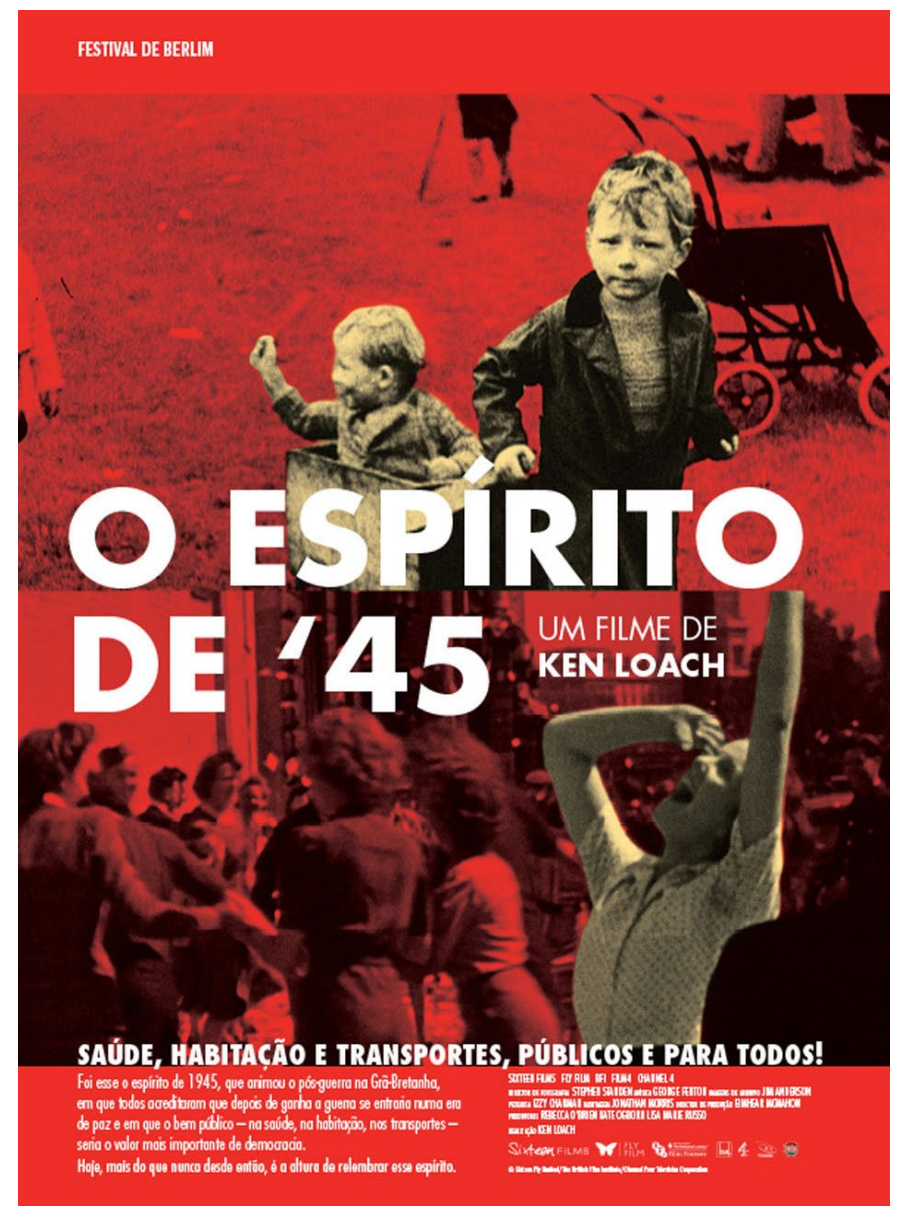




\section{Resumo}

Em 2018, o Sistema Único de Saúde (SUS) completou 30 anos de sua criação no Brasil. Embora reúna muitas conquistas nessas três décadas, o SUS hoje enfrenta novos desafios, impostos pela agenda liberal e conservadora em curso no país. Nesse contexto, o documentário O Espírito de 45 (2013), dirigido por Ken Loach, que destaca a criação do Serviço Nacional de Saúde (National Health Service - NHS), no Reino Unido, é um filme salutar. Tendo a cidadania e o bem comum como grandes temas, a obra mostra como é possível, revisitando o passado, despertar o espírito combativo em defesa de uma sociedade mais justa e solidária, que privilegie o bem-estar da população em lugar do lucro e que aponte caminhos para a defesa do SUS, enquanto uma conquista do povo brasileiro.

Palavras-chave: Documentário; Sistema Único de Saúde; National Health Service; Reforma Sanitária; Bem-estar social.

\section{Abstract}

In 2018, the SUS - Sistema Unificado de Saúde (Unified Health System) celebrated the 3oth anniversary of its setting up in Brazil. Despite its many achievements in these three decades, nowadays SUS faces new challenges which were imposed by a liberal and conservative agenda ongoing in the country. In this context, the documentary The Spirit of ' 45 (2013), directed by Ken Loach, which highlights the creation of the National Health Service (NHS) in the United Kingdom, is a very important film. Addressing citizenship and the common good as major themes, the movie shows how it is possible by revisiting the past to awaken the combative spirit in favour of a fairer and more solidary society, in order to prioritize the population's wellbeing instead of the profit and to point out ways to defend SUS as an achievement of the Brazilian people.

Keywords: Documentary, Sistema Único de Saúde; National Health Service (NHS); Health Care Reform; Social welfare.

\section{Resumen}

En 2018, el SUS - Sistema Único de Saúde (Sistema Único de Salud) completó 30 años de su creación en Brasil. Aunque haya tenido muchos logros en estas tres décadas, el SUS enfrenta hoy nuevos desafíos, impuestos por la agenda liberal y conservadora en curso en el país. En este contexto, la película documental The Spirit of ' 45 (2013), en la versión brasileña, O Espírito de 45, de Ken Loach, que destaca la creación del Servicio Nacional de Salud (National Health Service - NHS); en el Reino Unido, es un buen ejemplo. Con la ciudadanía y el bien común como temas principales, la producción muestra como es posible, reviviendo el pasado, despertar el espíritu combativo en defensa de una sociedad más justa y solidaria, que privilegie el bienestar de la población en lugar de losbeneficios lucrativos, y señale formas de defender el SUS, como un logro del pueblo brasileño.

Palabras clave: Documental; Sistema Único de Saúde; National Health Service; Reforma de la Atención de Salud; Bienestar social. 
Ficha técnica do documentário resenhado:

Título: O Espírito de 45. (título original: The Spirit of '45)

Direção: Ken Loach.

Produção: Fly Film Company.

Data de lançamento: 15 de março de 2013.

Duração: 94 minutos.

Contribuição dos autores: texto integralmente redigido pela autora.

Declaração de conflito de interesses: não há.

Fontes de financiamento: não há.

Agradecimentos/Contribuições adicionais: não há.

Histórico do artigo: submetido: 10 fev. 2020 | aceito: 20 abr. 2020 | publicado: 30 jun. 2020.

Apresentação anterior: não houve.

Licença CC BY-NC atribuição não comercial. Com essa licença é permitido acessar, baixar (download), copiar, imprimir, compartilhar, reutilizar e distribuir os artigos, desde que para uso não comercial e com a citação da fonte, conferindo os devidos créditos de autoria e menção à Reciis. Nesses casos, nenhuma permissão é necessária por parte dos autores ou dos editores.

Recentemente, em 2018, comemoramos os 30 anos da criação do Sistema Único de Saúde (SUS) ${ }^{1-3}$. Nessas três décadas, por meio do SUS, a saúde dos brasileiros melhorou significativamente com a instituição de programas e medidas que se tornaram referências para políticas públicas em todo o mundo. Segundo dados do Ministério da Saúde, o Programa Nacional de Imunização (PNI), por exemplo, garante à população acesso gratuito a todas as vacinas recomendadas pela Organização Mundial de Saúde (OMS). Atualmente, mais de 95\% dos transplantes realizados no País são financiados pelo (SUS), e trata-se do maior sistema público de transplantes do mundo . Nosso Sistema Único de Saúde também dá assistência integral e totalmente gratuita para a população de portadores do HIV e doentes de Aids, renais crônicos, pacientes com câncer, tuberculose e hanseníase.

O SUS é um sistema grandioso em seus feitos, mas também no número e na complexidade dos problemas que enfrenta ${ }^{5-7}$. Nascido na esteira da redemocratização do Brasil, o sistema sempre teve que lidar com o subfinanciamento crônico $^{8}$, problemas de gestão e uma fraca legitimação social. Hoje, somam-se a estes outros desafios, como as mudanças no perfil demográfico e epidemiológico da população brasileira - que vão onerar ainda mais os cofres públicos - e os diversos retrocessos no campo dos direitos sociais. $\mathrm{A}$ aprovação da Emenda Constitucional 95, que prevê o congelamento dos gastos em saúde por 20 anos e o aprofundamento das políticas de austeridade em curso colocam em sério risco as principais conquistas obtidas ao longo dos últimos $30 \operatorname{anos}^{9}$ e sufocam as tentativas de sobrevivência do sistema.

Nesse contexto, é salutar a obra do diretor Kenneth (Ken) Loach, em especial o documentário O Espírito de 45 (2013). O filme, que tem como ponto de partida o ano de 1945, retrata o clima na Inglaterra após o final da Segunda Guerra Mundial. Destaca-se a criação do Serviço Nacional de Saúde (NHS - National Health Service), um sistema de saúde universal em vigência até hoje, fruto das melhorias na vida da população com a ascensão do Partido Trabalhista ao poder.

Loach, que é filho de operários de Nuneaton, no Reino Unido, uma das cidades mais arrasadas durante a Segunda Guerra Mundial, não esconde seu alinhamento político à esquerda quando trata de conflitos sociais e da luta por direitos pelos trabalhadores durante os 94 minutos do documentário. Sua idade e origem são elementos fundamentais para compreender como o contexto político de seu território no 
pós-guerra é narrado com profunda humanidade. A experiência de vida do diretor acaba por estar contida nos afetuosos relatos de octogenários, que se entremeiam às ricas imagens históricas durante a narrativa.

O filme começa ambientando o clima, ou, nas palavras do diretor, o espírito daquela época: ao mesmo tempo, árido - em consequência dos abalos causados pelas duas recentes guerras - e esperançoso. O quadro histórico retrata a invisibilizada miséria na qual vivia parte da população e como a vida dessas pessoas muda para melhor a partir da gestão do primeiro-ministro Clement Attlee (1945-1951). A nacionalização de importantes indústrias e serviços, a implantação do Estado de bem-estar social e a criação do NHS são medidas que impactaram profundamente a vida da sociedade britânica na época, e que, em alguns casos, reverberam até hoje, como a questão sanitária. O acesso universal aos serviços de saúde de que a população da Grã-Bretanha dispõe na atualidade pode parecer algo trivial, mas, antes do NHS, era um luxo pelo qual poucos podiam pagar. No filme, mostra-se como as populações mais pobres sofriam e morriam por agravos simples. Com a implantação daquele serviço, esse estrato passou a poder contar com tratamentos e assistência médica adequados. "Meu avô só começou a usar óculos aos 7o anos, com a criação do NHS. Antes, sem dinheiro, lia usando um pedaço de vidro de fundo de garrafa à maneira de lupa", relata uma senhora.

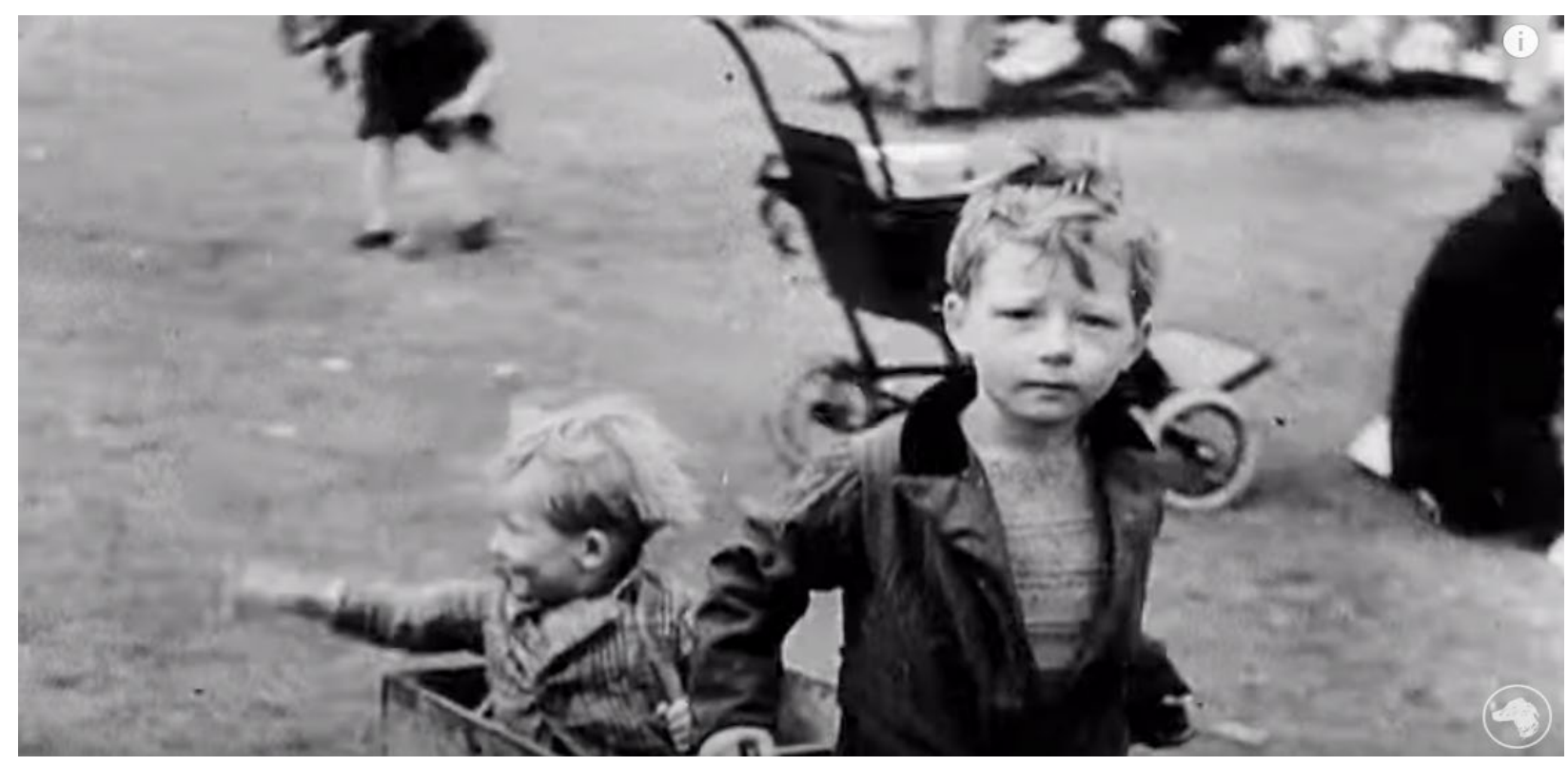

Figura 1 - O filme mostra a vida miserável em que parte da população da Grã-Bretanha vivia no pós- Guerra: as famílias não dispunham de condições de vida básicas e sobrevivam em locais insalubres e sem acesso a serviços de saúde Fonte: Youtube/Divulgação.

Entretanto, a partir da década de 1970, sob a gestão da primeira-ministra Margaret Thatcher, o individualismo começa a corroer o músculo coletivista que sustentava essas reformas e o setor privado avança mais profundamente. Loach mostra as consequências da redução do Estado de bem-estar social promovida pela Dama de Ferro. Os serviços de água, gás, aviação comercial, docas, eletricidade, portos e correios deixaram de ser estatais. E, mesmo naqueles segmentos nos quais não ocorreu a privatização integralmente, observa-se cada vez mais a contratação de empresas terceirizadas, como é o caso da área da saúde. E, se essa situação levou a índices elevados de desemprego e de aumento do trabalho informal, as imagens de repressão de manifestações populares mostram que não há espaço para a indignação popular. "Não há mais nenhum país para os pobres", constata uma das entrevistadas.

À guisa de conclusão, arriscamo-nos a dizer que a cidadania e o bem comum são os grandes temas que atravessam o Espírito de 1945. É uma afronta à lógica do consumo, que nos convida a pensar em nós mesmos menos como consumidores e mais como cidadãos. Uma das mensagens que Loach pode passar 
com sua obra é de que é possível, revisitando o passado, aguerrir o espírito combativo em defesa de uma sociedade mais justa e solidária, que privilegie o bem-estar da população em lugar do lucro e que aponte caminhos para a defesa do SUS, enquanto uma conquista do povo brasileiro.

É preciso agora reviver o Espírito de 88, ou seja, fazer brotar novamente o espírito democrático e de solidariedade social da Reforma Sanitária, para que o Estado possa atuar diretamente não só na questão da saúde, mas também em campos estratégicos que interferem na garantia desta como um direito social. Em um país de 207,7 milhões de habitantes e em que mais de 160 milhões dependem única e exclusivamente do Sistema Único de Saúde, defendê-lo, fortalecê-lo e ampliá-lo é uma tarefa fundamental ${ }^{10,11}$.

\section{Referências}

1. Paim JS, Temporão JG, Penna GO, Santos NR, Pinto LF. Sistema Único de Saúde: 30 anos de luta! [Internet]. Ciênc. saúde coletiva. 2018 jun [citado 19 fev. 2020];23(6):1704-04. doi: https://doi.org/10.1590/1413$\underline{81232018236.06612018}$.

2. Santos RT. SUS: um novo capítulo de lutas [Internet]. Ciênc. saúde coletiva. 2018 jun [citado 19 fev. 2020];23(6):1719-20. doi: https://doi.org/10.1590/1413-81232018236.05672018.

3. Leal L. Planos de Saúde [Internet]. Revista Poli: Educação, Saúde e Trabalho. 2011 mai/jun [citado 19 fev. 2020];3(17):18-20. Disponível em: http://www.epsjv.fiocruz.br/sites/default/files/revista_poli - 17.pdf.

4. Ministério da Saúde (BR). Sistema Único de Saúde financia 95\% dos transplantes no Brasil [Internet]. 2015 maio [citado 19 fev. 2020]. Disponível em http://www.brasil.gov.br/editoria/saude/2015/01/ sistema-unico-de-saude-financia-95-dos-transplantes-no-brasil.

5. Costa AM, Noronha JC, Noronha GS. Barreiras ao universalismo do sistema de saúde brasileiro. In: Tetelboin C, Laurell AC. Por el derecho universal a la salud: una agenda latinoamericana de análisis y lucha. Buenos Aires: CLACSO; 2015. p. 17-39.

6. Giovanella L. Sistemas de Saúde: origens, componentes e dinâmicas. In: Giovanella L, Escorel S, Lobato LVC, Noronha JC, Carvalho AI, organizadores. Políticas e Sistema de Saúde no Brasil. Rio de Janeiro: Fiocruz; 2012. p. 89-392.

7. Lima VA. Informação e Saúde Pública: a incapacidade do estado. In: Lima, VA. Regulação das Comunicações: história, poder e direitos. São Paulo: Paulus; 2011. p. 173-204.

8. Marques RM, Piola SF, Roa AC, organizadores. Sistema de saúde no Brasil: organização e financiamento [Internet]. Rio de Janeiro: Abres, 2016 [citado 19 fev. 2020]. Disponível em: http://economia.saude. homolog.bvs.br/lildbi/docsonline/get.php?id=140.

9. Castro MC, Massuda A, Almeida G, Menezes-Filho NA, Andrade MV, Noronha KVMS, et al. Brazil's unified health system: the first 30 years and prospects for the future [Internet]. The Lancet. 2019 [cited 19 fev. 2020] Jul 27; 394. Available from: https://www.thelancet.com/journals/lancet/article/PIIS01406736(19)31243-7/fulltext.

10. Campos GWS. Réplica: O SUS, todavia, existe! [Internet]. Ciênc. saúde coletiva. 2018 jun [citado 19 fev. 2020];23(6):1721-22. doi: https://doi.org/10.1590/1413-81232018236.05662018.

11. Noronha JC, Noronha GS, Pereira TR, Costa AM. Notas sobre o futuro do SUS: breve exame de caminhos e descaminhos trilhados em um horizonte de incertezas e desalentos [Internet]. Ciênc. saúde coletiva. 2018 Jun [citado 19 fev. 2020];23(6):2051-59. Disponível em: http://www.scielo.br/scielo. php?script=sci arttext\&pid=S1413-81232018000602051. 